\title{
Side Chain-Directed Assembly of Large Discotic $\pi$-Conjugated Molecules: Toward Tuning and Stabilization of Mesophases
}

\author{
Yusuke Tsutsui, ${ }^{1}$ Tsuneaki Sakurai, ${ }^{1 *}$ Kenichi Kato, ${ }^{2}$ Masaki Takata, ${ }^{2}$ and Shu Seki ${ }^{1 *}$ \\ ${ }^{1}$ Department of Applied Chemistry, Graduate School of Engineering, Osaka University, \\ 2-1 Yamadaoka, Suita, Osaka 565-0871, Japan. \\ ${ }^{2}$ RIKEN SPring-8 Center, 1-1-1 Kouto, Sayo-cho, Sayo-gun, Hyogo 679-5148, Japan. \\ E-mail: t-sakurai@chem.eng.osaka-u.ac.jp,seki@chem.eng.osaka-u.ac.jp
}

\begin{abstract}
A representative $\pi$-conjugated motif, perylenediimide (PDI), when functionalized with taper-shaped semi-fluoroalkyl chains at one of its imide positions, self-assembled into various ordered phase structures depending on the type of side chains at the other imide position. Asymmetrical substitution by semi-fluoroalkyl/alkyl chains allowed the PDI molecule to form a rectangular columnar liquid crystalline mesophase while semi-fluoroalkyl/ triethyleneglycol-substitution resulted in a lamellar-packed crystalline mesophase. In both mesophases, the immiscible nature of superhydrophobic/hydrophobic or superhydrophobic/hydrophilic segments works as the major droving force to lead semi-fluoroalkyl/alkyl or semi-fluoroalkyl/oxyethyleneglycol nano-domains, resulting in high stability of the mesophases with the wide temperature range over $100^{\circ} \mathrm{C}$. The compound decorated with tapered semi-fluoroalkyl chains at the both imide positions exhibited complicated crystalline ordered phases with high thermal stability.
\end{abstract}

keywords: liquid crystal, columnar phase, perylenediimide, immiscible chains

\section{Introduction}

Large $\pi$-conjugated molecules are of great interest because of their potential use as functional materials with optical, electrical, and magnetic properties. Such unique properties depend on not only the structure of $\pi$-systems itself but also their assembled structures. In particular, when focusing on their application as organic semiconductors, it is quite important how $\pi$-systems stack up to form long-range charge carrier transport pathways. ${ }^{1)}$ One of the promising approaches includes the peripheral modification of large $\pi$-systems with flexible chains that allows the formation of one-dimensional discotic columns via self-assembly. ${ }^{2-5)} \quad$ Although the diversity of central $\pi$-conjugated molecules has grown rapidly, long alkyl chains have been mostly utilized for large $\pi$-systems. Considering the fine-tuning of the $\pi$-stacking mode, morphology, and dimension of the structures to control the semiconducting property, there is still plenty room for improvement

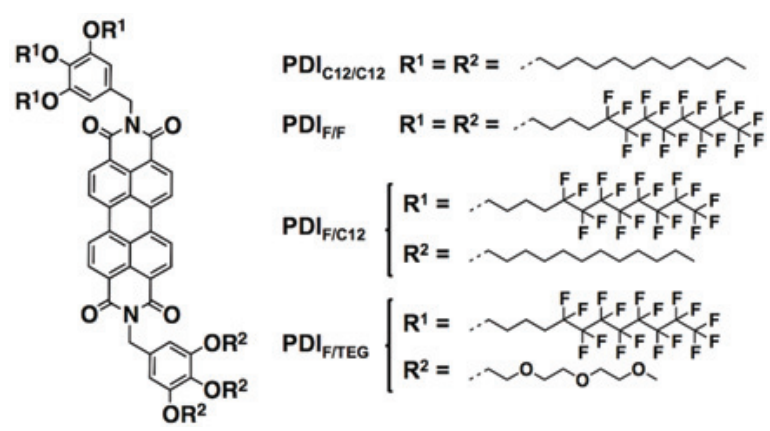

Fig. 1. Molecular structures of perylenediimide (PDI) derivatives having semi-fluoroalkyl side chains together with a reference PDI having alkyl chains.

hopefully given by side-chain engineering.

The strategy of side chain-directed assembly have been often reported for small aromatic compounds. Functionalization by long alkyl, fluoroalkyl, dimethylsiloxane, and triethyleneglycol chains triggers nano-segregation between the aromatic cores and respective chains, resulting in the formation of highly-ordered phase structures. $^{6-8)}$ In contrast, large $\pi$-system can 
form, without such additional interactions, columnar structures with two-dimensional periodic packing since strong $\pi-\pi$ stacking interaction operates together with the core/chain nano-segregation. ${ }^{2-5)}$ However, when incompatible side chain pairs were introduced to large $\pi$-conjugated cores, structural changes ${ }^{9-13)}$ were also observed, leading to the unique properties including enhancement of charge carrier mobility, ${ }^{9)}$ switching of dominant charge carriers, ${ }^{11)}$ photoluminescence color change ${ }^{13)}$, and so on. Here we report that perylenediimide (PDI) molecules carrying taper-shaped semi-fluoroalkyl chains at one imide position self-assembled into various type of ordered structures due to the strong self-aggregation character of fluoroalkyl segments. ${ }^{1415)}$ By tuning the type of chains at the other imide position of PDI (Fig. 1), we demonstrated both liquid crystalline (LC) and crystalline materials that show different macroscopic orientation capability.

\section{Experimental}

\subsection{General}

Unless otherwise noted, all commercial reagents were used as received. ${ }^{1} \mathrm{H}-\mathrm{NMR}$ spectra were recorded in $\mathrm{CDCl}_{3}$ on a JEOL model AL-400 spectrometer operating at $400 \mathrm{MHz}$. Polarized optical micrographs were recorded on a Nikon model ECLIPSE E600FN polarized optical microscope equipped with a hand-made hot stage and KPI model TC02 temperature controller. Differential scanning calorimetry measurements were performed on a Mettler model DSC $822 \mathrm{e}$ differential scanning calorimeter. Cooling and heating profiles were recorded and analyzed with a Mettler model STARe system. X-ray diffraction measurements were carried out using a synchrotron radiation X-ray beam with a wavelength of 0.108 $\mathrm{nm}$ on BL44B2 ${ }^{16)}$ at the Super Photon Ring (SPring-8, Hyogo, Japan). During the measurements, samples were put into a $0.5-\mathrm{mm}$ thick glass capillary and rotated and all diffraction patterns were recorded with a $0.01^{\circ}$ step in $2 \theta$. The exposure time to the X-ray beam was $3 \mathrm{~min}$. The temperature was controlled by high-temperature $\mathrm{N}_{2}$ gas flow. Heating and cooling process was controlled at a rate of $10^{\circ} \mathrm{C}$ $\min ^{-1}$ and the sample was annealed at the target temperature for $2 \mathrm{~min}$ prior to the beam exposure.

\subsection{Synthesis}

Synthetic schemes of PDI derivatives are described in Scheme 1. Compound $\mathbf{1}$ was synthesized in a similar way to the reported

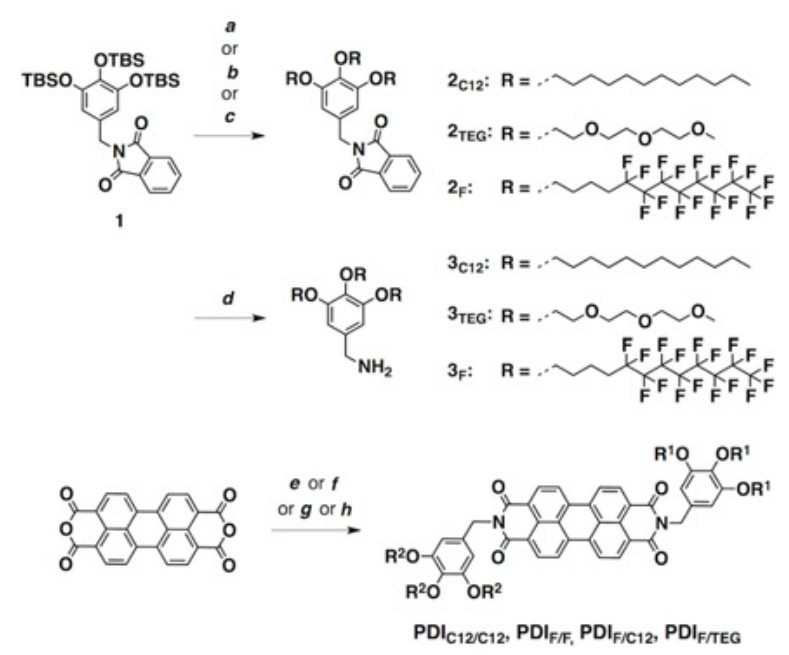

Scheme 1. Synthetic schemes of perylenediimide derivatives. (a) 1-bromododecane, $\mathrm{K}_{2} \mathrm{CO}_{3}, \mathrm{DMF}$, $80^{\circ} \mathrm{C}, 36 \mathrm{~h}$; (b) $\mathrm{TsO}\left(\mathrm{CH}_{2} \mathrm{CH}_{2} \mathrm{O}\right)_{3} \mathrm{Me}, \mathrm{K}_{2} \mathrm{CO}_{3}, \mathrm{DMF}$, $80^{\circ} \mathrm{C}, 24 \mathrm{~h}$; (c) $\mathrm{Br}\left(\mathrm{CH}_{2}\right)_{4}\left(\mathrm{CF}_{2}\right)_{8} \mathrm{~F}, \mathrm{~K}_{2} \mathrm{CO}_{3}, \mathrm{DMF}, 80^{\circ} \mathrm{C}$, $36 \mathrm{~h}$; (d) $\mathrm{H}_{2} \mathrm{~N}-\mathrm{NH}_{2} \cdot \mathrm{H}_{2} \mathrm{O}$, EtOH, reflux, $3 \mathrm{~h}$; (e) $\mathbf{3}_{\mathrm{C} 12}$, imidazole, pyridine, $90^{\circ} \mathrm{C}$; (f) $\mathbf{3}_{\mathrm{F}}$, imidazole, pyridine, $90^{\circ} \mathrm{C}, 18 \mathrm{~h}$; (g) $\mathbf{3}_{\mathbf{C 1} 2}, \mathbf{3}_{\mathrm{F}}$, imidazole, benzotrifluoride, pyridine, $90^{\circ} \mathrm{C}, 18 \mathrm{~h}$; (h) $\mathbf{3}_{\mathrm{TEG}}, \mathbf{3}_{\mathrm{F}}$, imidazole, benzotrifluoride, pyridine, $90^{\circ} \mathrm{C}, 18 \mathrm{~h}$.

procedure of 2-(3,4,5-tris(benzyloxy)benzyl) isoindoline-1,3-dione. ${ }^{17)}$

\section{Results and discussion}

The three compounds $\mathbf{P D I}_{\mathbf{F} / \mathbf{F}}, \mathbf{P D I}_{\mathbf{F} / \mathbf{C 1 2} \text {, and }}$ PDI $_{\text {F/TEG }}$ were newly synthesized according to the reported procedures with a slight modification. PDI $_{\mathbf{C 1 2 / C 1 2}}{ }^{18,19)}$ was also synthesized as a reference material exhibiting a typical hexagonal columnar LC phase. All the four compounds were characterized by ${ }^{1} \mathrm{H}$ NMR spectroscopy and MALDI-TOF-MS spectrometry. In differential scanning calorimetry (DSC), $\mathbf{P D I}_{\mathbf{C 1 2 / C 1 2}}$ showed a mesophase from -31 to $220^{\circ} \mathrm{C}$ on the second cooling process at a rate of $10^{\circ} \mathrm{C} \mathrm{min}^{-1}$ (Table 1). In the mesophase, birefringent textures were observed in polarized optical microscopy (POM) while the mesophase structure was assigned to a columnar hexagonal lattice by means of X-ray diffraction analysis (XRD), both of which are consistent with the previous reports. Having these in mind, the newly developed compounds were characterized in the identical methods. In the temperature region from -50 to $280^{\circ} \mathrm{C}, \mathbf{P D I}_{\mathbf{F} / \mathbf{F}}$ showed one solid-solid phase transition at around $242^{\circ} \mathrm{C}$ (Fig. 2a). $\quad$ PDI $_{\mathbf{F} / \mathbf{F}}$ appeared as powder, did not melt into isotropic liquid (IL) even over $300^{\circ} \mathrm{C}$, and exhibited poor solubility to common organic solvents. In addition, the powder showed birefringence in POM. Its XRD patterns at 300 
and $200^{\circ} \mathrm{C}$ both displayed a set of sharp diffraction peaks (Fig. 3a). Although it is difficult to assign these peaks to a simple crystalline lattice, we can conclude, based on the above observations, that self-aggregation of fluoroalkyl segments in $\mathbf{P D I} \mathbf{I}_{\mathbf{F} / \mathbf{F}}$ may be the major driving force to form crystalline phases rather than usual columnar LC phases as seen in $\mathbf{P D I}_{\mathbf{C 1 2 / C 1 2}}$.

In contrast, $\mathbf{P D I}_{\mathbf{F} / \mathbf{C 1 2}}$ behaves as a typical columnar LC but the phase structure is quite unique. $\mathbf{P D I}_{\mathbf{F} / \mathbf{C 1 2}}$ in DSC showed 4 and 3 times phase transitions on heating and cooling at $10{ }^{\circ} \mathrm{C}$ $\min ^{-1}$, respectively (Fig. 2b). The enthalpy changes at around $240^{\circ} \mathrm{C}$ indicated the phase transition between LC and IL phases, which was confirmed by microscopy and XRD measurements. Of interest, when cooled down from the IL to LC phase at $1{ }^{\circ} \mathrm{C} \mathrm{min}^{-1}$, the crossed polarized micrograph of $\mathbf{P D I}_{\mathbf{F} / \mathbf{C 1 2}}$ became dark while dendritic textures were seen in the optical micrograph (Fig. 2d). These features are characteristic of homeotropically oriented columnar LC phases. ${ }^{20,21)}$ In the slow-cooling condition, the LC nucleation may take place near the interface between LC and a glass substrate, and the columnar structures grow from each nucleus. Thus, the direction of the columns should be perpendicular to the glass substrates. In fact, birefringent textures appeared by the treatment of fast cooling at a rate of $20{ }^{\circ} \mathrm{C} \mathrm{min}{ }^{-1}$ (Fig. 2e). In the fast-cooling condition, many nuclei form in bulk, thus resulting in the formation of randomly-oriented LC domains. The observed spontaneous homeotropic alignment capability is important for the device-scale application of LC materials. ${ }^{20,21)}$ Based on the XRD pattern, we noticed that the structure of $\mathrm{Col}_{\mathrm{r} 2}$ phase of $\mathbf{P D I} \mathbf{I}_{\mathrm{F} / \mathrm{C} 12}$ (Table 1) was not a typical rectangular columnar phase with $p 2 \mathrm{~mm}$ symmetry. For example, (100) peak, usually not detected in common rectangular phases with high symmetry, was observed as seen in Fig. 3d. After complete assignment of all the obvious diffraction peaks, we found that the LC phase at $170^{\circ} \mathrm{C}$ was assigned to be a rectangular columnar lattice with $p 2 m g$ symmetry, where the lattice parameters of $a$ and $b$ are 60.7 and $34.1 \AA$, respectively. This structure can be explained as a result of side-chain immiscibility. ${ }^{10,11,22}$ Namely, dodecyl chains prefer to assemble with themselves and vice versa for the semifluoroalkyl chains. Therefore, to minimize the contact between dodecyl and fluoroalkyl domains, $\mathbf{P D I}_{\mathbf{F} / \mathbf{C} 12}$ molecules stack up to form columnar structures that further integrate into alternate immiscible nano-scale layers (Fig. 4a). When further cooled
Table 1. Phase behaviors with transition temperatures $\left({ }^{\circ} \mathrm{C}\right)$ on the second heating/cooling process at a rate of $10{ }^{\circ} \mathrm{C} \mathrm{min}^{-1}$. Transition enthalpies $\left(\mathrm{kJ} \mathrm{mol}^{-1}\right)$ are given in parentheses. Symbols $\mathrm{Cr}, \mathrm{G}, \mathrm{Col}_{\mathrm{h}}, \mathrm{Col}_{\mathrm{r}}, \mathrm{Col}_{\mathrm{x}}$, and IL denote crystalline, grassy, hexagonal columnar liquid crystalline, rectangular columnar liquid crystalline, unidentified columnar, and isotropic liquid phases, respectively.

\begin{tabular}{|c|c|c|c|c|c|c|}
\hline Entry & & Phase & $\stackrel{T_{\mathrm{t}} /{ }^{\circ} \mathrm{C}(\Delta H / \mathrm{l}}{\longleftarrow}$ & $\stackrel{\left(\mathrm{J} \mathrm{mol}^{-1}\right)}{\longrightarrow}$ & Phase & \\
\hline $\mathrm{PDI}_{\mathrm{C} 12 \mathrm{C} 12}$ & G & $\underset{-31(-16.3)}{\stackrel{-26(18.1)}{\rightleftarrows}} \mathrm{Col}_{h}$ & $\underset{220(-12.3)}{\stackrel{223(13.7)}{\rightleftarrows}}$ & IL & & \\
\hline $\mathrm{PDI}_{\mathrm{F} / \mathrm{F}}$ & $\mathrm{Cr}_{1}$ & $\stackrel{243(4.2)}{\stackrel{242(-3.3)}{\rightleftarrows}} \mathrm{Cr}_{2}$ & $92(13.4)$ & & & \\
\hline $\mathrm{PDI}_{\mathrm{F} / \mathrm{C} 12}$ & G & $\underset{10(-8.2)}{\stackrel{18(6.2)}{\rightleftarrows}}$ Col $_{r 1}$ & $\underset{88(-17.0)}{\stackrel{114(3.3)}{\rightleftarrows}}$ & $\mathrm{Col}_{12}$ & $\underset{239(-21.5)}{\stackrel{240(15.4)}{\rightleftarrows}}$ & IL \\
\hline $\mathrm{PDI}_{\mathrm{FTEG}}$ & G & 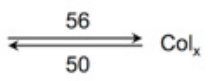 & $\underset{206(-4.1)}{\stackrel{211(4.4)}{\rightleftarrows}}$ & IL & & \\
\hline
\end{tabular}
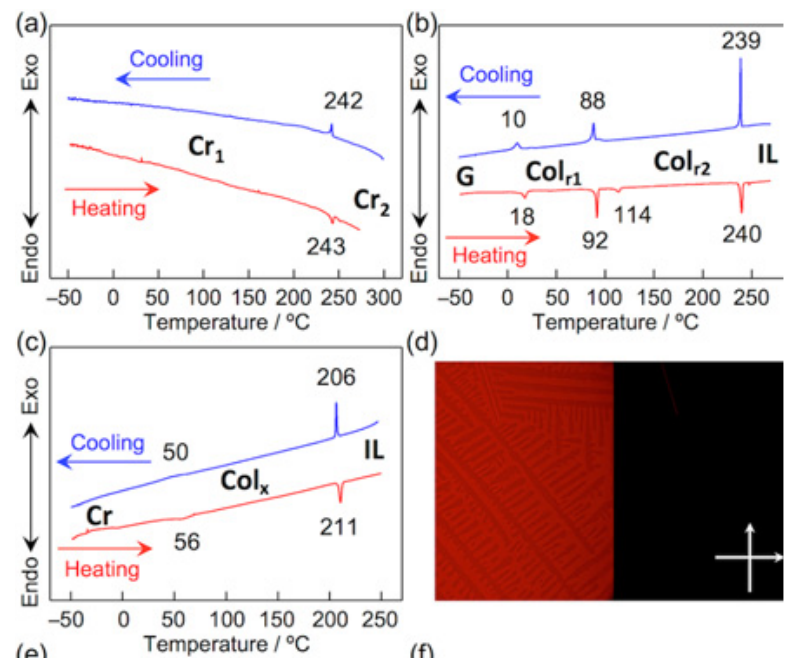

(e)

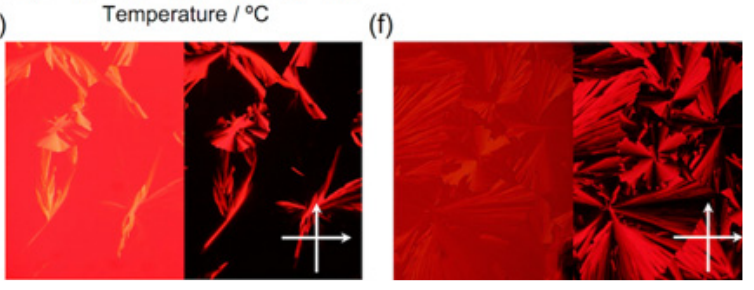

Fig. 2. Differential scanning calorimetry traces of (a) $\mathbf{P D I}_{\mathbf{F} / \mathbf{F}}$, (b) $\mathbf{P D I} \mathbf{F}_{\mathbf{F} / \mathbf{C 1 2}}$, and (c) PDI $\mathbf{I}_{\mathbf{F} / \mathbf{T E G}}$ on second heating and cooling processes at a rate of $10{ }^{\circ} \mathrm{C} \mathrm{min}-1$. Optical (left) and crossed polarized (right) micrographs of (d) $\mathbf{P D I}_{\mathbf{F} / \mathbf{C 1 2}}$ at $239^{\circ} \mathrm{C}$, (e) $\mathbf{P D I} I_{\mathbf{F} / \mathbf{C 1 2}}$ at $230^{\circ} \mathrm{C}$, and (f) $\mathbf{P D I}_{\mathbf{F} / \mathbf{T E G}}$ at $202^{\circ} \mathrm{C}$ in a sandwich-type glass cell. The samples were cooled from their isotropic liquid phase at a rate of $1{ }^{\circ} \mathrm{C} \min ^{-1}$ for (d) and (f) and $20{ }^{\circ} \mathrm{C} \mathrm{min}^{-1}$ for (e), respectively.

down, $\mathbf{P D I}_{\mathrm{F} / \mathrm{C} 12}$ undergoes a phase transition at around $90^{\circ} \mathrm{C}$ to exhibit $\mathrm{Col}_{\mathrm{r} 1}$ phase (Fig. 2b). According to the $\mathrm{XRD}$ pattern at $50^{\circ} \mathrm{C}$, the basic structure of $\mathrm{Col}_{\mathrm{r} 1}$ phase is similar to that of $\mathrm{Col}_{\mathrm{r} 2}$ except the appearance of sharp diffraction peaks at around $2 \theta=5,12$, and $18^{\circ}$ (Fig. 3e). These 

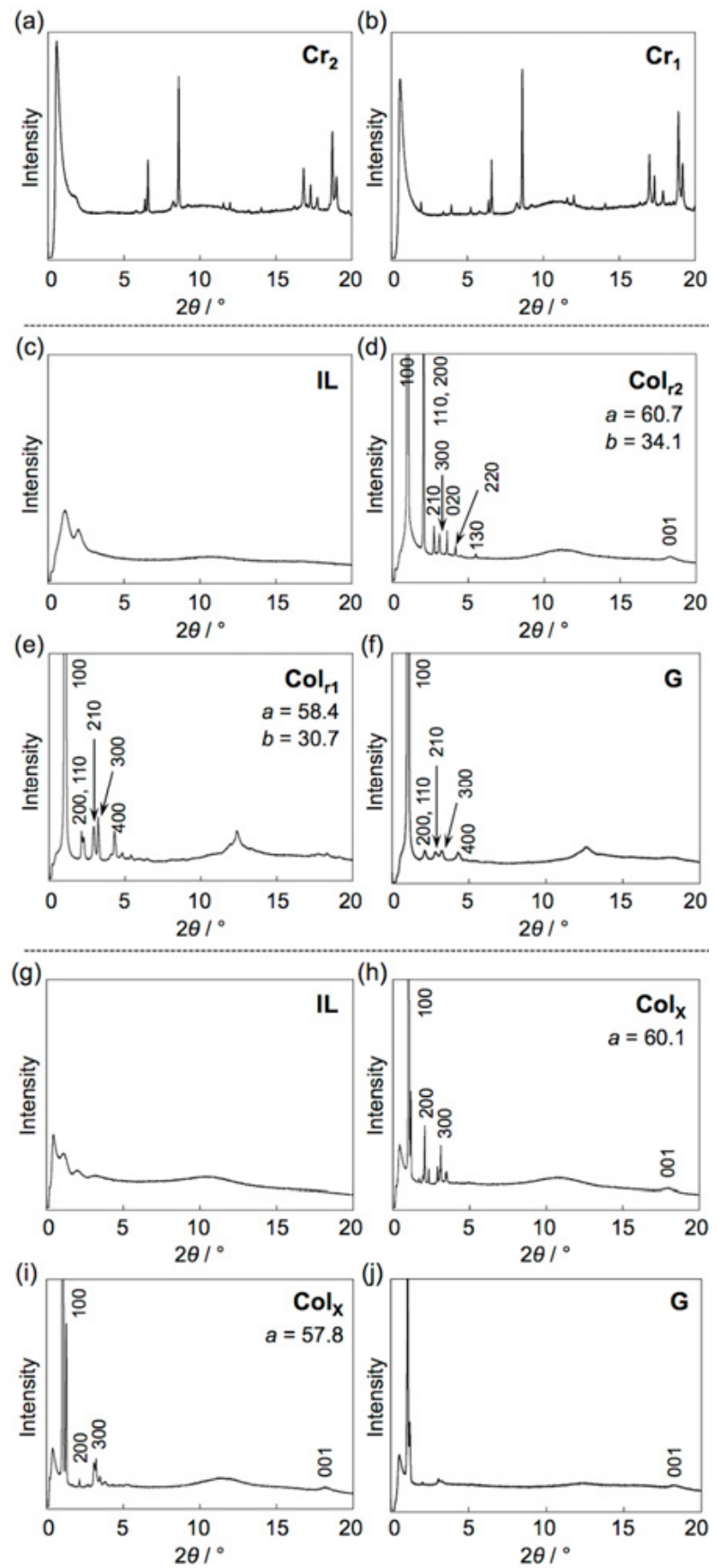

Fig. 3. X-ray diffraction patterns of $\mathbf{P D I}_{\mathbf{F} / \mathbf{F}}$ at (a) 300 ${ }^{\circ} \mathrm{C}$, and (b) $200{ }^{\circ} \mathrm{C}, \mathbf{P D I}_{\mathrm{F} / \mathrm{C} 12}$ at (c) $280{ }^{\circ} \mathrm{C}$, (d) $170{ }^{\circ} \mathrm{C}$, (e) $50^{\circ} \mathrm{C}$, and (f) $-30{ }^{\circ} \mathrm{C}$, and PDI $_{\text {F/TEG }}$ at (g) $250^{\circ} \mathrm{C}$, (h) $200{ }^{\circ} \mathrm{C}$, (i) $80^{\circ} \mathrm{C}$, and (j) $-30{ }^{\circ} \mathrm{C}$.

diffraction features may originate from the crystallization of fluoroalkyl chains that are known to interdigitate each other. ${ }^{15)}$

As shown in Fig. 3h, PDI $\mathbf{I}_{\text {/TEG }}$ indicated the $\pi$-stacking periodicity in its XRD pattern at $200^{\circ} \mathrm{C}$. Taking account of its DSC chart (Fig. 2c),

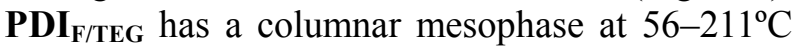
on heating and $206-50^{\circ} \mathrm{C}$ on cooling. However, we discovered that the mesophase was not a typical (a) Rectangular Columnar LC Phase ( $p 2 m g$ Space Group)

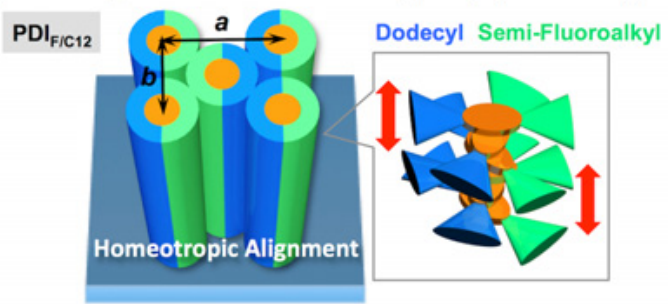

(b)

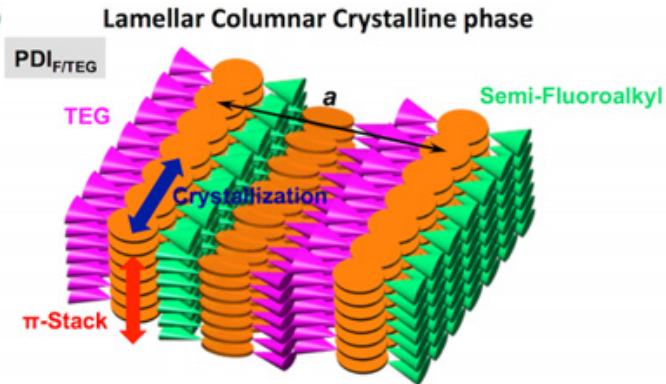

Fig. 4. Schematic illustration of molecular arrangement in (a) rectangular columnar liquid crystalline phase of $\mathbf{P D I}_{\mathbf{F} / \mathbf{C 1 2}}$ and (b) crystalline phase of PDI $_{\text {F/TEG }}$.

LC but crystal-like mesophase. Although the several strong diffraction peaks were assigned to a lamellar-based periodic structure (Figs. $3 \mathrm{~h}$ and 3i), there were still many minor diffractions that were difficult to assign. This mesophase was defined as $\mathrm{Col}_{\mathrm{X}}$. Nevertheless, the (100) diffraction $(d=$ $60.1 \AA$ ) of $\mathbf{P D I}_{\mathbf{F} / \mathrm{TEG}}$ at $200^{\circ} \mathrm{C}$ should correspond to the layered distance similar to the case of $\mathbf{P D I} \mathbf{I}_{\mathbf{F} / \mathbf{C 1 2}}$, giving the proposed packing structure as shown in Fig 4b. We thought that the extremely immiscible nature between the fluoroalkyl and triethyleneglycol chains would rule out the rectangular packing of the columnar structures and result in the lamellar-based structure without any contact between the fluoroalkyl and triethyleneglycol chains. Because of the absence of LC character, PDI $_{\text {F/TEG }}$ did not show homeotropic alignment capability even in the slow cooling condition at $1{ }^{\circ} \mathrm{C} \mathrm{min}^{-1}$ from its IL phase (Fig. 2f).

\section{Conclusion}

Toward the fine-tuning of structures, morphology, and $\pi$-stacking mode of self-assembled perylenediimide (PDI) motifs, we have developed a side-chain strategy including taper-shaped semifluoroalkyl chains. When both imide positions were decorated with these chains, resulting $\mathbf{P D I}_{\mathbf{F} / \mathbf{F}}$ formed crystalline phases having high thermal stability. By replacing one of the imide positions with tapered alkyl chains $\left(\mathbf{P D I}_{\mathbf{F} / \mathbf{C 1 2})}\right)$, columnar liquid crystalline mesophases with $p 2 m g$ symmetry were appeared as a result of 
minimizing the contact between dodecyl and fluoroalkyl domains. When a tapered semifluoroalkyl and triethyleneglycol pair was employed (PDI $\left.\mathbf{P}_{\mathbf{F} / \mathbf{T E G}}\right)$, a lamellar-based crystalline mesophase was developed as an ultimate structure to avoid the contact between these incompatible chains. Interplay of $\pi$-stacking interactions and nano-segregation via introduction of immiscible side chain pairs in the orthogonal direction would be a general strategy to form stable mesophases from disc-shaped large $\pi$-conjugated molecules.

\section{Acknowledgements}

This work was partly supported by a Grant-in-Aid for Young Scientists (B) (26810049) from the Japan Society for the Promotion of Science. We thank Prof. Dr. Aida and Mr. Shibuya in The Univ. of Tokyo for DSC measurements. The synchrotron radiation experiments were performed at BL44B2 ${ }^{16)}$ in SPring- 8 with the approval of RIKEN (Proposal No. 20130021).

\section{References}

1. V. Lemaur, D. Da Silva Filho, V. Coropceanu, M. Lehmann, Y. H. Geerts, J. Piris, M. G. Debije, A. M. van de Craats, K. Senthilkumar, L. D. A. Siebbeles, J. M. Warman, J.-L. Brédas, J. Cornil, J. Am. Chem. Soc. 126 (2004) 3271.

2. D. Adam, P. Schuhmacher, J. Simmerer, L. Häussling, Nature 371 (1994) 141.

3. S. Laschat, A. Baro, N. Steinke, F. Giesselmann, C. Haegele, G. Scalia, R. Judele, E. Kapatsina, S. Sauer, A. Schreivogel, M. Tosoni, Angew Chem. Int. Ed. 46 (2007) 4832.

4. S. Sergeyev, W. Pisula, Y. H. Geerts, Chem. Soc. Rev. 36 (2007) 1902.

5. W. Pisula, M. Zorn, J. Y. Chang, K. Müllen, R. Zentel, Macromol. Rapid Commun. 30 (2009) 1179.

6. C. Tschierske, J. Mater. Chem. 11 (2001) 2647.

7. M. Lehmann, Chem. Eur. J. 15 (2009) 3638.

8. C. Tschierske, Angew. Chem. Int. Ed. 52 (2013) 8828.

9. X. Feng, V. Marcon, W. Pisula, M. R. Hansen, J. Kirkpatrick, F. Grozema, D. Andrienko, K.
Kremer, K. Müllen, Nature Mater. 8 (2009) 421.

10. T. Sakurai, K. Shi, H. Sato, K. Tashiro, A. Osuka, A. Saeki, S. Seki, S. Tagawa, S. Sasaki, H. Masunaga, K. Osaka, M. Takata, T. Aida, J. Am. Chem. Soc. 130 (2008) 13812.

11. T. Sakurai, K. Tashiro, Y. Honsho, A. Saeki, S. Seki, A. Osuka, A. Muranaka, M. Uchiyama, J. Kim, S. Ha, K. Kato, M. Takata, T. Aida, J. Am. Chem. Soc. 133 (2011) 6537.

12. M.-C. Yeh, Y.-L. Su, M.-C. Tzeng, C. W. Ong, T. Kajitani, H. Enozawa, M. Takata, Y. Koizumi, A. Saeki, S. Seki, T. Fukushima, Angew. Chem. Int. Ed. 52 (2013) 1031.

13. S. Yagai, S. Okamura, Y. Nakano, M. Yamauchi, K. Kishikawa, T. Karatsu, A. Kitamura, A. Ueno, D. Kuzuhara, H. Yamada, T. Seki, H. Ito, Nature Commun. 5 (2014) 5013.

14. T. Doi, Y. Sakurai, A. Tamatani, S. Takenaka, S. Kusabayashi, Y. Nishihata, H. Terauchi, $J$. Mater. Chem. 1 (1991) 169.

15. M. P. Krafft, J. G. Riess, Chem. Rev. 109 (2009) 1714.

16. K. Kato, R. Hirose, M. Takemoto, S. Ha, J. Kim, M. Higuchi, R. Matsuda, S. Kitagawa, M. Takata, AIP Conf. Proc. 1234 (2010) 875.

17. V. Percec, H.-J. Sun, P. Leowanawat, M. Peterca, R. Graf, H. W. Spiess, X. Zeng, G. Ungar, P. A. Heiney, J. Am. Chem. Soc. 135 (2013) 4129.

18. Z. An, J. Yu, S. C. Jones, S. Barlow, S. Yoo, B. Domercq, P. Prins, L. D. A. Siebbeles, B. Kippelen, S. R. Marder, Adv. Mater. 17 (2005) 2580.

19. V. Percec, H.-J. Sun, P. Leowanawat, M. Peterca, R. Graf, H. W. Spiess, X. Zeng, G. Ungar, P. A. Heiney, J. Am. Chem. Soc. 135 (2013) 4129.

20. J. Piris, M. G. Debije, N. Stutzmann, B. W. Laursen, W. Pisula, M. D. Watson, T. Bjørnholm, K. Müllen, J. M. Warman, $A d v$. Funct. Mater. 14 (2004) 1053.

21. M. Yoshio, T. Kagata, K. Hoshino, T. Mukai, H. Ohno, T. Kato, J. Am. Chem. Soc. 128 (2006) 5570.

22. M. Lehmann, M. Jahr, J. Gutmann, J. Mater. Chem. 18 (2008) 2995. 